\title{
CONSCIÊNCIA IMAGINANTE E CONSCIÊNCIA REFLEXIVA: UMA HISTÓRIA DO TEATRO DE PORTO ALEGRE A PARTIR DE IMAGENS E AUTOIMAGENS
}

\author{
Carina Zatti Corá \\ Mestranda no Programa de Pós-graduação em Artes Cênicas da Universidade Federal do Rio Grande do Sul \\ carina.zatti.cora@gmail.com \\ Clóvis Dias Massa \\ Doutor em Letras pela Pontifícia Universidade Católica do Rio Grande do Sul. \\ Professor associado do Departamento de Arte Dramática \\ e do Programa de Pós-graduação em Artes Cênicas da Universidade Federal do Rio Grande do Sul \\ clovisdmassa@gmail.com.br
}

O presente trabalho estabelece noções de convergência e divergência com relação à imagem construída pelos artistas de si próprios e do teatro de Porto Alegre. As fontes principais da pesquisa são os relatos orais dos diretores de teatro Adriane Mottola e Élcio Rossini sobre suas trajetórias artísticas, a partir dos conceitos de imagem e consciência, de Jean-Paul Sartre, e de autoimagem, de Richard Cándida Smith. Busca-se reconhecer os diferentes pontos de vista levantados por esses artistas e analisar as imagens mentais recorrentes sobre o teatro portoalegrense, com base no uso da História Oral como procedimento e produção de conhecimento, sem a pretensão de criar uma imagem unívoca e totalizante do teatro na cidade.

\section{Palavras-chave}

Teatro em Porto Alegre. História Oral. Imagem. Autoimagem.
This article proposes to establish similarities and differences in relation to the concept of the self-image of artists and the concept of the image of the theater made in Porto Alegre. The main sources of the research are the oral reports of theater directors Adriane Mottola and Élcio Rossini on their artistic trajectories, based on the concepts of Jean-Paul Sartre's image and consciousness, and the self-image of Richard Candide Smith. The article seeks to recognize the different points of view raised by these artists and to analyze the recurrent mental images about the theater in Porto Alegre, from the use of Oral History as a procedure and production of knowledge, without the pretension of creating a univocal and totalizing image of theater in the city.

Keywords

Theater in Porto Alegre. Oral History. Image. Self-image. 


\section{Introdução}

Nessa investigação não se analisam fotografias e vídeos do teatro de Porto Alegre, mas imagens do teatro que surgem das falas de dois artistas locais em seus relatos orais. Como não há como ter acesso direto à imagem mental, recorre-se às palavras que as expressam, por meio da descrição. As entrevistas de História Oral são uma oportunidade de rever e organizar o passado tanto para si como para o outro (no caso, os pesquisadores) e, desse modo, os entrevistados vão percebendo sua transformação enquanto artistas como consequência de suas diversas experiências ao longo do tempo, num processo de autoconhecimento.

Como as imagens trabalhadas são o cerne da questão, não sendo de natureza sólida, e sim flexível e efêmera tal qual a memória, buscou-se em O Imaginário, de Jean-Paul Sartre, a compreensão sobre o conceito de imagem como ato. Sartre considera a imagem como uma forma de consciência, acabando com a ideia de imanência em voga até então, na qual a imagem é vista como coisa imutável e a consciência como lugar, o receptáculo das imagens (SARTRE, 1996, p.17). Sendo assim, a imagem passa a ser tratada como consciência imaginante. Portanto, a consciência imaginante é sempre a consciência de alguma coisa.

A maneira como cada um se enxerga em um determinado contexto de suas vidas é sua autoimagem. É importante lembrar que a autoimagem dos artistas está ligada ao que eles desejam passar para o ouvinte da entrevista. Sendo um meio acadêmico e tendo os pesquisadores como ouvintes, os entrevistados criam uma autoimagem social focada em seus interlocutores, priorizando relatos que possam transmitir sua consolidação no terreno teatral, ou seja, focando em sua autoimagem artística.

Quanto à possibilidade de mudança da autoimagem, o historiador Richard Cándida Smith observa que, durante a fala, o 'eu narrativo' vai se construindo, desenvolvendo-se, criando outras autoimagens para si em relação ao contexto vivido. (SMITH, 2002, p. 38) $\mathrm{Na}$ qualidade de entrevista de História Oral, os artistas puderam falar livremente, sem a condução direta dos pesquisadores, mas com algumas colocações pontuais por parte deles, a fim de esclarecer aspectos da narração. Conforme princípios metodológicos formulados pelo próprio grupo de pesquisa, as entrevistas foram inicialmente transcritas para depois ser elaborado um resumo de cada um dos registros, a fim de ser anexado à transcrição das mesmas, como forma de sintetizar os pontos fundamentais de cada coleta. Somente então se partiu para a análise de dados referentes à autoimagem e imagem dos sujeitos entrevistados, por meio da identificação dos tópicos com o sistema de legenda de cores.

Imagens e autoimagens dos sujeitos

Élcio Rossini é doutor em Poéticas Visuais pelo Programa de Pósgraduação em Artes Visuais da Universidade Federal do Rio Grande do Sul, diretor teatral e cenógrafo. Adriane Mottola é mestre em Artes Cênicas pelo Programa de Pósgraduação em Artes Cênicas da mesma instituição, diretora e atriz na Cia. Teatro di Stravaganza. ${ }^{1}$ Adriane e Élcio entraram

1 Ambos foram entrevistados no gabinete da Pesquisa História e Perspectivas do Teatro em Porto Alegre, no Departamento de Arte Dramática da Universidade Federal do Rio Grande do Sul, nos anos de 2014 e 2015. Tanto Adriane Mottola como Élcio Rossini tem contato próximo com a instituição acadê- 
no teatro por acaso. Ambos citam a timidez como mola propulsora para começar a atuar, e não como um ponto negativo em sua carreira. Élcio cursava artes visuais quando, nos anos 1980 , teve seu primeiro contato com o teatro em uma disciplina que unia professores das três artes.

Eu sempre fui muito tímido, mas ao mesmo tempo sempre foi um prazer enorme improvisar e poder fazer as coisas. E foi com a... Haydée Porto. E tinha uma disciplina, eu vou voltar essa história, porque como eu estou trabalhando na universidade, estou trabalhando na graduação, eu vejo hoje como é importante os artistas, tanto nas artes visuais quanto no teatro, se integrarem um pouco, verem o que acontece nas outras áreas. Porque hoje é um requisito importante. E tinha uma disciplina que se chamava Experiências Integradas I e II, e era com três professores, um da música, um das artes visuais e um do teatro. Essa experiência foi marcante pra mim, então desde o início, por algum motivo, me saí bem, mesmo sendo tímido. $\mathrm{E}$ aí já tinha coisas acontecendo, tava o Paulo Conte, a Adriane Mottola... Ah! Essas pessoas assim com as quais eu comecei a trabalhar aqui... E aconteceu também uma coisa mais absurda ainda. Eu tinha uns amigos, eu fui numa festa (risada), e aí eu tava dançando, aí o Balaio de Gatos, a Neca Menna Barreto me convidou para participar do grupo que ela trabalhava, que era o Balaio de Gatos. E aí eu fiz uma participação com eles, e a minha história com teatro começou assim. Mas desde a graduação que eu fiz em artes visuais, como eu fiz o mestrado e doutorado também nas artes visuais, o meu vínculo com teatro começou na graduação por essa via. Então eu me considero um artista que transita entre as duas áreas com propriedade, as-

mica da pesquisa - foram professores substitutos do Departamento de Artes Dramática da UFRGS. Sendo professores (Élcio leciona atualmente na Universidade Federal de Santa Maria), tanto um como o outro tem o costume de refletir sobre seus trabalhos artísticos, e a presença dos pesquisadores e o local da entrevista não os intimidaram. sim. Eu conheço bem as duas áreas, não sou um expert em teatro, mas eu transito bem entre as duas áreas. (ROSSINI, 2015)

Já o contato de Adriane se deu através de amigas que cursavam teatro na UFRGS. A referência de Élcio, em um primeiro momento, é muito mais a de um artista visual do que a de um artista de teatro. No caso de Adriane, as artes visuais aparecem fortemente ligadas ao seu trabalho, principalmente, graças à presença do antigo companheiro Luiz Henrique Palese, com quem fundou a Cia. Teatro di Stravaganza.

O Stravaganza surge com um grupo de três pessoas, que éramos eu, o Cacá Correa e o Luiz Henrique Palese. Nós nos juntamos para criar um espetáculo que era infantil. Então, nos primeiros anos da companhia, nos primeiros cinco anos - isso foi em 88, então esses primeiros cinco anos a gente basicamente criou espetáculos infantis. O Palese era artista visual, né, ele havia feito faculdade de Artes Visuais e o Cacá também. E eu é que tinha passado passado pelo DAD, estava ainda no DAD naquele momento. Aí, então a gente se juntou.... Então tinha uma estética meio forte porque o Palese era figurinista, cenógrafo, iluminador. Ele já tinha participado de um grupo chamado Faltou o João, que era um grupo da época. (MOTTOLA, 2014)

Adriane Mottola mostra-se como atriz e diretora e se enxerga como uma pessoa que incomoda. Confessa, bem humorada, que 'inferniza' a vida dos diretores e quer sempre se impôr perante eles. $E$ isso fez com que buscasse espaço não só na atuação, mas também na direção. Sua trajetória é bem estruturada em seu discurso, visto que faz parte de um grupo e descreve com clareza as diferentes linguagens exploradas pelo Stravaganza ao longo do 
tempo. Sua confiança como artista e integrante de um grupo cresceu com os prêmios ganhos pelos espetáculos. Como acredita possuir um "energia bem brasileira", que quer levar para os espetáculos, isso se reflete em um trabalho de atmosfera popular, festiva e com muita fisicalidade. Além disso, vê-se como uma diretora que quer fazer com que as ideias nasçam dos atores, que eles tenham fé no que fazem. Em seu discurso, na maior parte do tempo Adriane Mottola alterna a primeira pessoa do plural com a expressão "a gente" (como substitutivo do pronome "nós"), sendo difícil identificá-la sem esclarecer que ela trata de si como parte de um grupo sólido:

A gente não pensa bem assim ("oh, esse ano a gente vai montar um teatro de rua"). A gente escolhe o que vai fazer e aí pensa "mas isso aqui combina pra rua". Mas nós não somos um grupo de teatro de rua, entendeu? Nós fizemos muito pouca coisa de teatro de rua. Nós fizemos uns três ou quatro espetáculos, no máximo. E a gente não se considera da rua, mas aconteceu já. No ano passado a gente estava muito interessado em montar um texto... Vou voltar um pouquinho. A gente se interessou muito pela intervenção urbana há uns dois anos atrás. Então trabalhamos com várias pessoas com intervenção urbana, começamos a trabalhar nós mesmos e montamos um grupo que funcionou, acho que um ano e meio. Até no ano passado a gente fez várias intervenções, apresentações no Palco Giratório, foi bem bacana e enfim. E aí parecia que a gente tinha entrado mais por esse caminho de intervenção urbana, mas a gente é um grupo que muda muito. Mas, de qualquer forma, como eu estava dizendo, a gente montou um texto e achou que ele tinha muito a ver com o teatro de rua e a gente até encaminhou pro FUMPROARTE um projeto de espetáculo para a rua. Eu acho que o último tinha sido Sacra Folia mesmo. Faz muito, muito tempo. Então vamos ver se sai, se vai adiante. (MOTTOLA, 2014)
A ideia que Adriane tem de si é a de ser muito mais da prática do que da teoria teatral. Ao acreditar que, na sua prática, sempre se pode ir além, busca enveredar por novos caminhos para depois descobrir no que os atores posteriormente vão se aprofundar. Essa necessidade de mudança e de novidade compõe a essência de sua autoimagem:

Eu procuro ir descobrindo o tempo todo, ir descobrindo com o enrolar. Não o enrolar no mal sentido, mas como encaminhar, como encaminhar os atores para que eles sejam genuínos naquilo que fazem, porque é só isso que a gente tenta fazer, que eles tenham fé naquilo que estão fazendo e acho que com o processo isso vai acontecendo. Acho que as resistências no início do processo de trabalho são normais, mas depois que o trabaIho engrena, que tu encontra a engrenagem de seja lá o que o trabalho vai expressar e acho que é um trabalho de fé mesmo. A gente começa um processo longo principalmente desacreditando dele e nossa fé vai crescendo e vai vendo o que os outros estão fazendo, aí tu trabalha em conjunto... A gente trabalha muito com os próprios atores construindo a cena, então a gente dá um tema e os atores vão improvisar em cima daquilo, sabe? Ou então um ator vai dirigir os outros, um pedacinho da cena tal e então meu trabalho é montar com aquilo que foi criado. (MOTTOLA, 2014)

Deste modo, a "autoimagem de artista" de Adriane Mottola é calcada no coletivo do grupo, a necessidade do grupo ter uma sede foi sempre uma questão fundamental para determinar a identidade do núcleo: "Tu é misturado com tudo, parece que tu não é reconhecível, mas se tu tem teu lugar, aquelas pessoas entendem quem tu é." (MOTTOLA, 2014) Podese perceber que há uma necessidade de delimitar as fronteiras do seu grupo, como parte de um princípio identitário. 
Diferentemente de Adriane, o diretor Élcio Rossini se enxerga como um artista independente, sem nunca ter pertencido regularmente a uma companhia de teatro. Ele considera que sempre quis se aproximar do teatro, apesar de ser formado em artes visuais: "Eu podia ajudar muito além da cenografia. Podia colaborar abrindo as possibilidades da palavra teatro." (ROSSINI, 2015). Élcio esteve, no início de sua trajetória, em conflito sobre ser artista visual ou artista de teatro, e isso gerou uma falta de continuidade em sua carreira, pois, na época, segundo ele mesmo, não era comum unir as artes visuais às artes cênicas, e isso fez com que seu trabalho ficasse segmentado em momentos mais cênicos ou mais plásticos.

Essa vontade de colocar suas impressões de forma mais direta sobre o produto artístico também o levou da atuação para a direção. Por mais que não tenha se fixado num só grupo ou tido sede própria, salienta que ganhou muito mais confiança quando lutou por espaços públicos para realizar espetáculos. $\mathrm{O}$ diretor conta que possuir a chave da Cia. de Arte, do Armazém B do Cais do Porto e da llha da Casa de Pólvora, quando ficou à frente de projetos artísticos em diferentes momentos de sua carreira, fez com que pudesse afirmar que tem o vigor para conquistar seu espaço.

A Cia. de Arte estava fechando. Essa eu acho uma referência importante. São nove andares na Cia. de Arte. A Cia. de Arte era uma associação de funcionários da Caixa Econômica Federal que estava se mudando para a sua sede na zona sul. E só tinha um andar funcionando para atender os funcionários, era uma radiologia, eu não me lembro o que é que tinha ali. Daí o Ricardo, que era presidente da associação, disponbilizou uma sala na Cia. de Arte. Então, durante um ano, um ano, nós trabalhamos lá. E eu tinha o primeiro andar, e nós ficávamos de noite, nove andares vazios, e a gente andando pelos andares, recolhendo coisas. Então eu tinha um vestiário cheio de objetos, tudo que eu tinha, eu levava pra lá, tudo que eu encontrava, eu levava pra lá. Então as pessoa que estiveram lá e que foram muito importantes, a Tatiana Cardoso, a Jezebel de Carli e a Ciça Recksziegel, essas três pessoas foram fundamentais... $E$ foram passando outras pessoas. $E$ Fábio Milan. Com esses eu fiquei um ano. Depois veio o Clóvis (Massa) que ficou um período, o Lauro (Ramalho) que ficou um período, muitas pessoas foram e viram... ah... entravam e saiam, mas, assim, com esses, eu passei um ano e aprendi muito, nós improvisávamos todas as noites, todas as noites. E a gente tinha um foco. Porque nesse período nós ganhamos o primeiro FUMPROARTE. Com uma proposta que eu tinha feito que chamava de um acontecimento teatral, eu queria fazer uma coisa que tinha a ver com o parque de diversões, que tinha a ver com quermesse, e a gente fez o Parque Extremo de Diversões. Ganhamos dinheiro, mas era tão pouco pra tanta gente, e levou um ano a elaboração. Mas acho que essa foi a minha melhor formação fora da academia, trabalhar com essas pessoas que tinham um grande conhecimento, então foi um prazer. (ROSSINI, 2015)

No caso de Élcio, essa questão vai mais além, visto que ele generaliza quando fala sobre a classe artística, tomando em consideração não ter ganho prêmios em um festival "durante um bom tempo" como uma crítica de toda a classe aos seus trabalhos. Esse sentimento de falta de pertencimento na classe teatral provém da autoimagem de Élcio como não tendo conhecimento suficiente de teatro e de treinamento de ator para ser considerado um bom diretor. "Eu não sabia nada de teatro, mas tinha muita vontade de criar." (ROSSINI, 2015) Apesar desta autoimagem, o espetáculo de maior sucesso de Élcio, em determinado período de sua carreira, seria focado nas po- 
tências de atuação da atriz llana Kaplan, e não na plasticidade das artes visuais. Assim como na entrevista de Adriane, percebe-se a necessidade de aceitação pela classe artística através de prêmios aos seus trabalhos. Em contraponto com o sentido de grupalidade presencial de Adriane, Élcio trabalha com outros artistas através de diálogos pelas redes sociais, algumas de suas criações nos últimos anos estão no âmbito de criação de acontecimentos esvaziados de espetacularização através de performances e de imagens potentes desses acontecimentos registradas em fotografia.

A autoimagem de Élcio na atualidade não é a de um ator ou diretor, e sim a de artista, livre de categorias. "Porque é uma coisa que a gente mesmo se autoriza, né, dizer que eu transito entre esses dois campos." (ROSSINI, 2015) Podemos perceber, nesta frase, a afirmação da autoimagem de artista das duas áreas, que navega entre grupos e artes.

Da consciência imaginante à consciência reflexiva: o teatro de ontem

Será a palavra um tipo de imagem? Esta problematização foi, de certa forma, respondida por Jean-Paul Sartre, pois, para ele, a palavra é um signo que forma uma ponte entre o mundo imaginário e o mundo real. Sartre coloca que a linguagem é uma forma de dar precisão ao pensamento, pois tomamos conhecimento dele através da fala. (SARTRE, 1996, p.117) Assim, a palavra é produzida por uma série de movimentos da glote, constituindo um fenômeno acústico representante da imagem mental. Quando a palavra tem a função de representar uma imagem, pois nem sempre há a formação de imagem no fluxo de pensamento, ela é considerada por Sartre como signo colado à imagem, conceito que será aqui utilizado.

Ao tratar a imagem como consciência, Sartre esclarece que há muitos tipos de consciência, e que a relação de sucessão harmônica entre elas é a responsável por criar o pensamento. Porém, o filósofo não se atém sobre essas outras formas de consciência, e nos deparamos com a exigência de encontrar uma terminologia para falar sobre o pensamento em fluxo, livre de imagens. Percebeu-se esta necessidade a partir da pesquisa empírica nas entrevistas de História Oral com artistas de teatro de Porto Alegre, sendo que, na maior parte do tempo, os sujeitos não formam imagens mentais, apenas refletem sobre suas trajetórias. Para tanto, chegou-se à noção de consciência reflexiva, ou seja, uma consciência como resultado da consciência imaginante fomentada durante a entrevista. Deu-se o nome de consciência reflexiva em virtude da reflexão que os artistas fazem de suas trajetórias, sendo uma noção elaborada especificamente em relação aos relatos desses sujeitos.

O primeiro exemplo que aparece no relato de Adriane Mottola é a consciência imaginante do grupo Stravaganza, com seus integrantes se reunindo para brincar de escrever a dramaturgia do espetáculo. Já a noção de consciência reflexiva se define por uma consciência livre de imagens que ocorre durante a entrevista, diretamente relacionada à reflexão realizada dos entrevistados durante o relato, e que pode induzir à criação de uma consciência imaginante. Para que isso ocorra, é necessário um gatilho imaginante, que pode ser o contexto, a pessoa, um objeto que está no fluxo de pensamento e que engatilha a formação de uma imagem mental. A fim de melhor exempli- 
ficar como acreditamos que esse processo de criação de imagens ocorre durante a fala dos sujeitos, criou-se um diagrama (Figura 1):

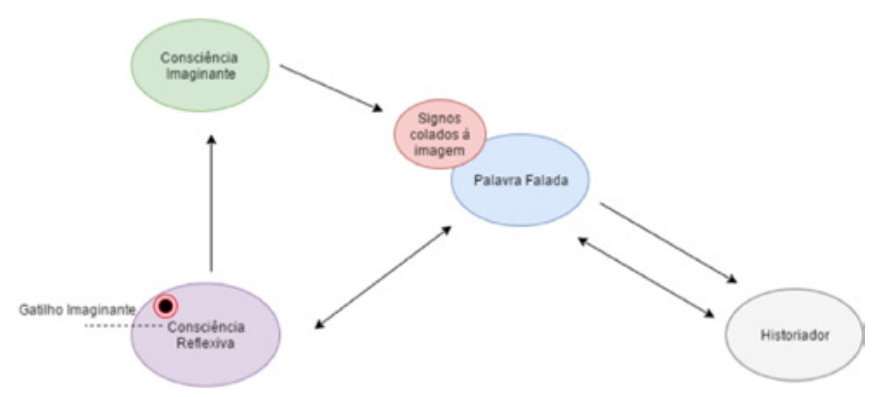

Figura 1

A consciência reflexiva (representada pelo círculo de cor roxa) versa sobre um assunto, pessoa ou contexto e é comunicada para o historiador (entrevistador) através da palavra falada (o círculo de cor azul). O historiador, através de resposta falada, também pode interferir no rumo do pensamento do entrevistado, quando faz uma pergunta ou sinaliza algo pontualmente através de sua expressão corporal. Quando um assunto trazido pela consciência reflexiva evoca uma consciência imaginante, ocorre um gatilho imaginante (representado pelo círculo preto inserido no círculo roxo). A consciência imaginante (círculo verde) é expressada através de signos colados à imagem (círculo vermelho), que formam uma categoria dentro da palavra falada, referente a palavras que expressam a imagem mental. Desse modo, o historiador tem acesso a esses signos e nunca à imagem em si. Portanto, o ciclo é contínuo, visto que a imagem provoca um novo fluxo de pensamento ou a continuação do fluxo anterior, formando uma nova consciência reflexiva. Num primeiro momento, por exemplo, a consciência reflexiva de Adriane detém-se sobre a forma como se dava a criação do grupo em seus primeiros anos. Esse fluxo de pensamen- to evoca uma imagem - a consciência imaginante de brincadeiras textuais realizadas na casa dos integrantes do grupo.

$\mathrm{Na}$ continuidade do relato de Adriane, a consciência reflexiva sobre a dramaturgia evoca uma nova consciência imaginante, a de um teatro em Montevideu com mais de mil pessoas na platéia para assistir ao espetáculo $O$ Ovo de Colombo, da Cia. Stravanganza, de 1992. Os signos colados à imagem que se formam são expressados por Adriane na entrevista: "Nosso trabalho era uma coisa um pouco diferente do que se fazia na época." (MOTTOLA, 2014)

O grupo Stravaganza decidira por um trabaIho que pudesse ser entendido pela fisicalidade bem trabalhada, e não pela fala, criando o espetáculo Decameron, em 1993, no qual utilizavam apenas o dialeto italiano. Desse modo, os principais signos colados à imagem mental para expressar a história aos espectadores não eram da ordem de palavras, e sim da corporeidade e dos gestos.

A peça Decameron e sua linguagem evocaram a atmosfera da commedia dell'arte em muitos espectadores. A partir de sugestões, - Stravaganza começou a trabalhar com essa linguagem com enfoque brasileiro. A peça também trazia o signo da peste bubônica, do amor e sexo. E eles serviram de gatilhos imaginantes para a questão da AIDS, a doença que acometera a sociedade nos anos 90 e da qual pouco se sabia na época.

Duas consciências imaginantes são engatiIhadas deste contexto. A primeira é a de uma apresentação do espetáculo em Recife, onde ninguém tinha contato com o idioma italiano, e que mesmo assim fora um sucesso. A outra consciência imaginante é a do pai de Luiz Henrique Palese, um senhor italiano, ajudando o grupo a pronunciar as palavras e a decorar o 
texto, visto que, na ocasião, eles não dominavam o idioma. (Figura 2: O lado direito da imagem representa o primeiro processo, e o lado esquerdo mostra a continuação do ciclo.)

Com relação à mesma montagem, a consciência imaginante de uma cena realizada por Luiz Henrique Palese e Roberto Oliveira é evocada. A cena era calcada somente nas ações de ambos durante um longo tempo sem perder a graça: "um batia na parede furioso, aí o outro batia no chão furioso, aí o outro se batia na cara furioso... cada vez ia aumentando mais aquilo e sempre era engraçado, eles conseguiam." (MOTTOLA, 2014)

Um palco quase vazio, com somente o corpo do ator na cena, e o cenário como sendo praticamente uma ambientação, é a essência desse trabalho do grupo, na visão de Adriane. Ao mesmo tempo, o contexto de atores que entram e saem da companhia faz com que alguns espetáculos alterem completamente sua dinâmica: "Uma correria, peças sendo apresentadas ao mesmo tempo, pessoas sempre indo e vindo. É bem complexo." (MOTTOLA, 2014)

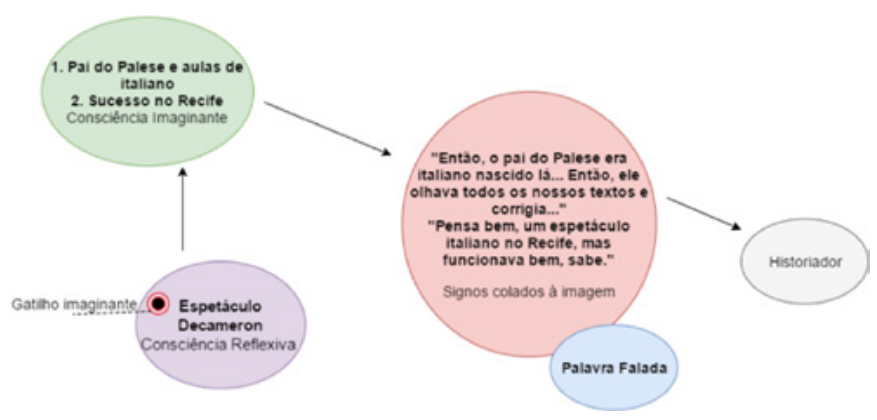

Figura 2

Outra imagem mental que surge durante a entrevista é a de uma garagem com sete boxes, numa área enorme de manobra coberta, referência à sede da Cia Stravaganza, no bairro Santana, utilizada para ensaios e de- pósito do material de trabalho e cenários. A consciência imaginante de todos construindo aquele espaço, colocando o chão, pintando as paredes, significa que aquele é um espaço construído pelos artistas, onde eles guardam todo material, onde eles criam. As palavras coladas à imagem da sede da companhia são sintetizadas na frase: "É um lugar todo especial." (MOTTOLA, 2014) Faxinas coletivas feitas pelos integrantes do grupo mostram a relação de cuidado de todos com o espaço. A sede de seu grupo propicia uma consciência reflexiva sobre como era fazer teatro na época em relação a ter um público fiel: "As pessoas te escrevem, deixam coisas, ligam perguntando quando é que vai ter um outro espetáculo." (MOTTOLA, 2014)

Falando sobre o último espetáculo do Stravaganza, Estremeço², de 2012, surge a aurora de imagens composta por luz, movimentos precisos e frieza europeia. Quando uma consciência imaginante não chega a se criar completamente, e há somente borrões de imagens e sensações, Sartre chama esse fato de aurora de imagens (SARTRE, 1996, p.89). Adriane gostaria que o espetáculo tivesse atmosfera dionisíaca que teria a ver com a brasilidade e a festividade do grupo, mas a peça tem tendência apolínea.

Por sua vez, Élcio começa seu relato falando sobre sua primeira experiência como espectador. Ele se expressa de forma vaga com as seguintes descrições da imagem de $A$ Bicicleta do Condenado ${ }^{3}$, de 1979, espetáculo da Tribo de Atuadores Ói Nóis Aqui Traveiz: "Um monte de jornal, não se sabia o que tinha ali, começaram a se mexer, lançavam carne." (ROSSI-

2 Texto de Joël Pommerat, com direção de Camila Bauer.

3 Texto de Fernando Arrabal. Encenação do grupo Ói Nóis Aqui Traveiz. 
NI, 2015) Élcio também opera a consciência reflexiva da imagem evocada, retornando a um fluxo de pensamento sem imagens, relembrando as diferenças da recepção do espetáculo: "Sentei-me ao lado de Gerd Bornheim, meu amigo, e tivemos impressões diferentes sobre o espetáculo." (ROSSINI, 2015) Gerd Bornhein, célebre filósofo e crítico do teatro, tinha muito mais conhecimento na área do que Élcio, tendo tido outra avaliação da peça. Para relatar as diferentes impressões causadas pela encenação, Élcio faz uso de signos colados à consciência imaginante desta lembrança. "Eu achei aquilo uma maravilha! Já Gerd Bornheim o classificou como ridículo!” (ROSSINI, 2015)

No caso de Élcio, tem-se a imagem de sua primeira ida ao teatro, quando jovem. Esse contexto cria um gatilho imaginante que gera a consciência imaginante de uma festa, na qual Élcio dançara com seus amigos. A imagem da festa faz com que Élcio retorne ao fluxo de pensamento, criando uma consciência reflexiva sobre ser este o contexto no qual ele fora convidado pela então atriz Neca Menna Barretto para participar do seu grupo, Balaio de Gatos. Ao citar a trupe Balaio de Gatos, criase um segundo gatilho imaginante que gera a consciência imaginante de uma apresentação que fez com o grupo no Cio da Terra, festival de música que reuniu mais de 20 mil pessoal nos Pavilhões da Festa da Uva de Caxias do Sul, em outubro de 1982. Essa imagem chega ao historiador novamente através de signos. (Figura 3: O lado direito da imagem representa o primeiro processo, e o lado esquerdo mostra a continuação do ciclo.)

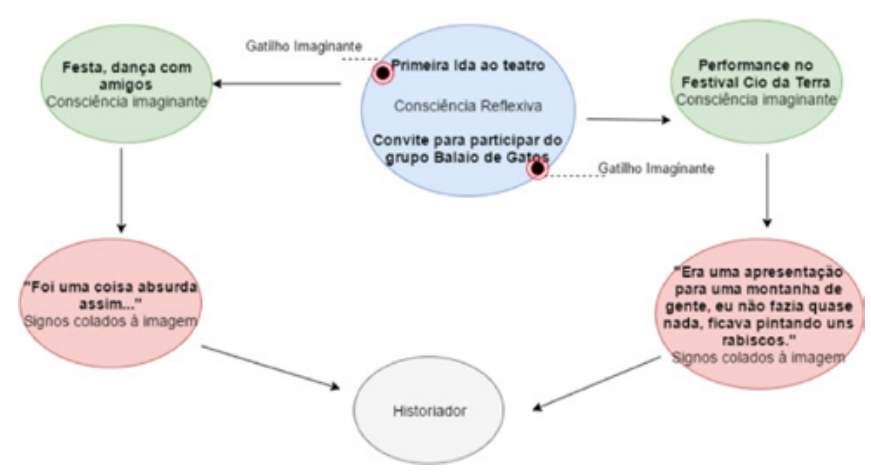

Figura 3

Em sua busca por algo que não fosse nem só teatro nem só artes visuais, Élcio povoa de imagens lúdicas ao se referir à montagem de Parque Extremo de Diversões ${ }^{4}$, de 1996. A consciência imaginante evocada do espetáculo é bastante rica, o cais do porto repleto de atrações simultâneas e quermesses. $\mathrm{Na}$ ocasião, as atrizes faziam pão no início do espetáculo e, depois de pronto, compartilhavamno com o público ao final da peça. Élcio traz sua consciência reflexiva sobre a imagem do amassar e dividir o pão, acreditando que a comida promove o encontro entre as pessoas.

Como uma coisa leva à outra, a consciência reflexiva da comida como evento de comunhão serve como gatilho para a consciência imaginante de Élcio no tempo em que morava em São Paulo e trabalhava na organização de um buffet, juntamente com Neca Menna Barreto. Quando sobrava comida, eles faziam uma festa e aproveitavam o que não tinha sido consumido. Os signos colados à imagem mental de Élcio descrevem muito bem aquele momento em sua vida: "Casa no fundo do terreno, toda cercada, com portão amarelo. Não se via, só se ouvia." (ROSSINI, 2015) A memória não é só constituída por uma imagem mental, mas também por sons. É neste contexto que as ima-

4 Argumento, roteiro e direção de Élcio Rossini. 
gens mentais de esculturas efêmeras de gelo e fogo formam-se, relatando os experimentos que ali começou a fazer com o intuito levar a efemeridade do teatro para as artes visuais.

A consciência imaginante salta para a Casa de Cultura Mário Quintana cheia de artistas que tramavam balões. As palavras coladas à imagem nos ajudam a entender: "Tramas com balão linguiça, que lindo, que potência. As pessoas simplesmente tramavam balões." (ROSSINI, 2015) Élcio trazia tarefas, e queria esvaziá-las de todo aspecto espetacular. Através da repetição, uma performance engraçada com pessoas trocando de roupa ou mexendo com objetos infláveis se tornava chata, vazia. A partir desses objetos para ações e performances, Élcio conseguiu estabelecer um trâmite entre artes visuais e teatro. Ao falar sobre as performances, surge a consciência imaginante de sua casa, uma banheira de ferro, e de Élcio servindo seus convidados enquanto eles tomavam banho. Essa série de performances dos banhos na casa de Élcio foram retratadas em exposição fotográfica. "Eu convidava pessoas para tomarem banho na minha casa. Como eu morava em um apartamento, eu comprei uma banheira de ferro, mandei fazer uns pés e botei uma banheira lá. Claro, não tinha aquecimento, não tinha nada. A gente ficava então servindo as pessoas e providenciando água quente, e durava mais ou menos uma hora." (ROSSINI, 2015) Outra performance que lhe evoca imagens mentais é Figuras e Fantasmas ${ }^{5}$, um de seus últimos projetos, no qual as pessoas vestem diversas roupas para, em seguida, tirá-las. No início, a ação é cômica, mas vai se tornando cansativa pela repetição, e é esse o objetivo de Élcio. A imagem mental de dois homens

5 Performance com direção de Élcio Rossini e participação de Thiago Pirajira e Júlia Rodrigues. sem cabeça, as cabeças escondidas dentro das camisas, é explicada com palavras: "Se formam imagens ridículas, mas elas vão se esvaziando." (ROSSINI, 2015)

\section{Imagens e tendências} do teatro de Porto Alegre hoje

Adriane apresenta uma imagem crítica do Teatro em Porto Alegre, reiterada ao longo de sua entrevista. Quando fala sobre o importante papel de Luciano Alabarse no desenvolvimento do teatro da cidade, remonta à criação do Festival Internacional de Teatro Porto Alegre em Cena ${ }^{6}$, em 1993, e se refere à Sessão Maldita $^{7}$, em 1995 - a narrativa à leva ao alçapão do palco do teatro Renascença, para se chegar nas estruturas internas do teatro. Já para falar do teatro no presente, ela evoca uma dança dos teatros públicos, uma expressão para exemplificar que não há mais sedes para os grupos e nem um público fiel, já que os artistas estão à mercê dos teatros e da vontade dos técnicos, visto que são os únicos que tem a garantia de pagamento fixo por seu trabalho. A consciência de um público impaciente que não sabe o que está passando no teatro é forte em seu discurso. Outra imagem que é evocada ao criticar o teatro da cidade é a da presença dos musicais. Ela se expressa da seguinte forma: "Tudo tá virando musical por aqui. Agora tudo que é cantor ou compositor morto já tem musical." (MOTTOLA, 2014) Segundo ela, o musical e a comédia stand up constituem o teatro

6 Festival de Teatro da Secretaria Municipal de Cultura de Porto Alegre, idealizado e organizado por Luciano Alabarse.

7 Projeto da Secretaria Municipal de Cultura realizado no porão do Teatro Renascença, que semanalmente, à meia-noite, apresentava espetáculos de caráter experimental. 
popular contemporâneo, sendo considerados "uma chatice". (idem).

Élcio também propõe uma consciência reflexiva entre o teatro que se faz hoje e que se fez em Porto Alegre há tempos atrás. A consciência de um cruzamento entre as artes surge somente a partir dos anos 2000 , acredita ele, quando o hibridismo e o atravessamento entre as artes tornou-se difundido no fazer teatral da cidade. Outra grande mudança é a questão de renda, muito mais fragilizada hoje em dia em comparação com os anos 1980, período em que conseguiu comprar e mobiliar um apartamento com o dinheiro da bilheteria da peça Passagem para Java ${ }^{8}$, em 1986. Diferente dessa época, atualmente os grupos ficam na dependência somente de editais públicos de fomento. A consciência imaginante do apartamento adquirido por meio do trabalho com teatro, de tão distante que está do contexto de hoje, é difícil de se acreditar. O uso da tecnologia também é um ponto positivo no teatro atual, conforme ele, pois permite a realização de trocas criativas entre artistas, através das redes sociais, sendo o uso da tecnologia importante referência do seu trabalho na atualidade. "Então eu quero encontrar um veículo para isso, é um vídeo, eu não sei, eu tô pensando em fazer uma página do facebook. Eu tô experimentando. Vai ter uma forma isso, mas eu não sei qual." (ROSSINI, 2015)

Por fim, Élcio Rossini, por não possuir um grupo nem uma sede, ao evocar a consciência imaginante da Cia. de Arte, num prédio que outrora fora da Caixa Econômica Federal, instituindo num prédio de nove andares, sem infraestrutura e manutenção, mas cheio de

8 Coletânea de textos de Clarice Lispector, Julio Cortázar, Miguel Magno e Ricardo Almeida. Direção de Élcio Rossini, atuação Ilana Kaplan. objetos e artistas criativos improvisando e se fazendo atuantes, traduzem uma imagem potente do Teatro em Porto Alegre.

\section{Considerações finais}

Através do estudo da imagem, partindo-se da História Oral, é possível encontrar pontos de encontro e desencontro na trajetória de artistas, sendo uma maneira de, através da comparação, retratar o contexto e a imagem do teatro em Porto Alegre, passando pela visão dos entrevistados e pela interpretação dos pesquisadores. Tanto as obras de Élcio Rossini como de Adriane Mottola adentram o terreno da novidade, da experimentação e da espontaneidade. Ambos têm uma forte conexão com as artes visuais, o que promove uma linguagem e estética claras em seu teatro. Adriane e Élcio, com seus trabalhos, também promovem consciências imaginantes em seus espectadores não somente através da palavra, mas pelas ações físicas ou performáticas que propõem. Ambos artistas possuíam uma auto-imagem de timidez e incerteza quanto ao futuro profissional no teatro, porém seu crescimento artístico e suas visões de si mesmo continuamente se retroalimentam e auxiliam uma a outra a evoluir. Entretanto, as divergências são também fortes e constroem na imagem do teatro de Porto Alegre linhas de força. Élcio acredita no cruzamento entre as artes e se vê como um artista autônomo e transitório. Por outro lado, Adriane é parte da Cia. Stravaganza, e sua auto-imagem é extremamente ligada ao grupo. Ela também se enxerga potente nos trabalhos de atriz e diretora, tendo as artes cênicas como foco em sua carreira. As consciências imaginantes que formam as 
lembranças dos sujeitos compõem uma criação sensível, quase artística para os pesquisadores, que pescam imagens e autoimagens a fim de compor a imagem do teatro portoalegrense. Um teatro permeado por energia brasileira, tradições de teatro de feira, teatro de rua e sala, atmosferas apolíneas e dionisíacas, repleto de ações esvaziadas e performances com objetos, de textos criados em sala de ensaio por atores, de atores que dirigem e de artistas visuais que também dirigem espetáculos, ideias, obras. Um teatro de muitas facetas e consciências imaginantes que, através deste estudo, podem alimentar um pouco mais o imaginário do teatro porto alegrense e sua carência documental.

Referências

ALABARSE, Luciano. Alguns diretores e muita conversa: entrevistas com diretores de teatro que trabalham em Porto Alegre. Porto Alegre: SCM, 2000.

MOTTOLA, Adriane. Câmara do Livro. Disponível em: http://www.camaradolivro.com.br/ autores_det.php?id=182. Acesso em 22 de setembro de 2015.

Cia. Stravaganza: um olhar sobre os processos criativos no teatro de grupo, 2009, 192 p. Dissertação de Mestrado. Programa de Pós-graduação em Artes Cênicas, UFRGS, Porto Alegre, 2009. Disponível em: http://hdl. handle.net/10183/17891. Acesso em: 3 out. 2015.
- Entrevista concedida a Clóvis Dias Massa. Departamento de Arte Dramática. Porto Alegre, 2014.

ROSSINI, Élcio. Blog de Élcio Rossini. Disponível em: http://elciorossini.blogspot.com.br/. Acesso em: 22 set. 2015.

- Entrevista concedida a Clóvis Dias Massa. Departamento de Arte Dramática. Porto Alegre, 2015.

SARTRE, Jean-Paul. O Imaginário. São Paulo: Ática, 1996.

SMITH, Richard Cándida. Circuitos de subjetividade: história oral, o acervo e as artes. São Paulo: Letra e Voz, 2012.

"Tribo de Atuadores Ói Nóis Aqui Traveiz." Enciclopédia Itaú Cultural. Disponível em: http:// enciclopedia.itaucultural.org.br/grupo387844/ oi-nois-aqui-traveiz. Acesso em: 5 out. 2015.

Recebido: 28/12/2015

Aprovado: 15/12/2016 